Article

\title{
Smart Facility Management: Future Healthcare Organization through Indoor Positioning Systems in the Light of Enterprise BIM
}

\author{
Tor Åsmund Evjen ${ }^{1}$, Seyed Reza Hosseini Raviz ${ }^{2, *}$, Sobah Abbas Petersen ${ }^{2}$ \\ and John Krogstie ${ }^{2}$ (i) \\ 1 St. Olavs Hospital, Abels gate 5 St. Olavs Eiendom, 7034 Trondheim, Norway; Tor.Asmund.Evjen@stolav.no \\ 2 Department of Computer Science, NTNU-Norwegian University of Science and Technology, \\ 7491 Trondheim, Norway; sobah.a.petersen@ntnu.no (S.A.P.); john.krogstie@ntnu.no (J.K.) \\ * Correspondence: seyed.r.h.raviz@ntnu.no
}

Received: 19 June 2020; Accepted: 23 July 2020; Published: 1 August 2020

check for updates

\begin{abstract}
Synthesizing the Internet of Things (IoT) with building information modeling (BIM) can improve the performance of the data collection. In this regard, BIM endeavors to enable real-time monitoring conditions of buildings. This paper is focused on the indoor positioning system (IPS) as a key enabling technology for IoT applications, which uses smart and non-smart mobile devices (object tags and beacons) with the aim of positioning and objects tracking that lead to a smart approach in the field of facility management (FM). Hence, we have surveyed the joint use of IPS and BIM in FM based on the concept of enterprise BIM (EBIM). EBIM forms the basis for the future strategic real estate management using virtual models and open standards. As a result, we gained the ability to collect positioning data continuously, save them in a BIM database, and present them on two-dimensional (2D) maps. This is a part of an ongoing study that aims to use data collection effectively for FM as an organizational function in large and complex buildings. Hence, for this purpose, we have considered St. Olavs Hospital, one of the biggest healthcare centers in Norway, as a case study. The effectiveness of data collection by IoT devices installed in buildings and how the combination of BIM and IoT technology can support a holistic view of the status of the buildings, which subsequently can enhance data usage efficiency and FM development, will be demonstrated.
\end{abstract}

Keywords: Internet of Things (IoT); building information modeling (BIM); indoor positioning system(IPS); enterprise BIM (EBIM); facility management (FM)

\section{Introduction}

According to the requirements, service expectations related to buildings are evolving over the course of time, while the equipment that are used for various purposes are subjected to aging and erosion. The main duty of smart buildings, compared to conventional buildings, is making enhancement and functional efficiency for its users and owners by using data and information communication technology. The development of smart buildings is tied to the advancement of smart technologies and this has brought many new phenomena into the construction industry that change ownership, user and management environments. Optimal and truly functional smart buildings incorporate engineering and non-technical aspects that should be taken into consideration throughout all life cycle phases. This needs the emergence of completely new expertise or the scaling up of existing proficiency, including facility management. Smart and functional facility management can contribute to cost savings and lead to easy resource utilization [1]. In this regard, Internet of Things (IoT) technology will change the way buildings are functioned and maintained. This gives rise to efficiencies and cost savings that 
result from responsiveness and reactivity of the new system. The development of the IoT will permit managers to have a better understanding of how people use buildings, leading to new maintenance approaches, better design, and finally more productive spaces [2]. This means that by changing the perspective of productivity and facility management, smart buildings provide useful, integrated and intelligent services that create the lowest environmental impacts and costs throughout the life cycle of the building. In fact, smart buildings utilize information technology to exchange data in real time. In this regard, interoperability, empowering equipment through unified information generated by a platform of the Internet of Things (IoT), and artificial intelligence (AI) are the most important leverage factors. In general, smart buildings offer a wide range of benefits and services within a good working environment to owners, facility managers, and inhabitants and they act as an additional service platform according to the needs of the stakeholders [3]. Hence, careful preparation within the building planning and highly professional management and maintenance during operation are the key roles in facility management [1].

Indoor positioning systems (IPS) contributed to increased functional efficiency and making fundamental development in many types of industries and organizations. In this regard, many companies employ the new possibilities and functionalities found in IPS solutions. The most considerable advantage of using IPS in the industry is its significance and usage potential in establishing and developing new services [4]. In fact, IPS is a set of software and hardware solutions that permits the position and situation of people or objects wirelessly inside buildings (Figure 1). IPS are integrative and inclusive systems that are aimed to be a part of the converging technologies, and they have been designed to work in a mutually reinforcing and synergic manner. These systems are in charge of gathering raw and unprocessed data with the help of sensors for later use and by means of software and applications of location estimation techniques. They transform this information into representations of physical locations that are comprehensible and intelligible to the final user [5].

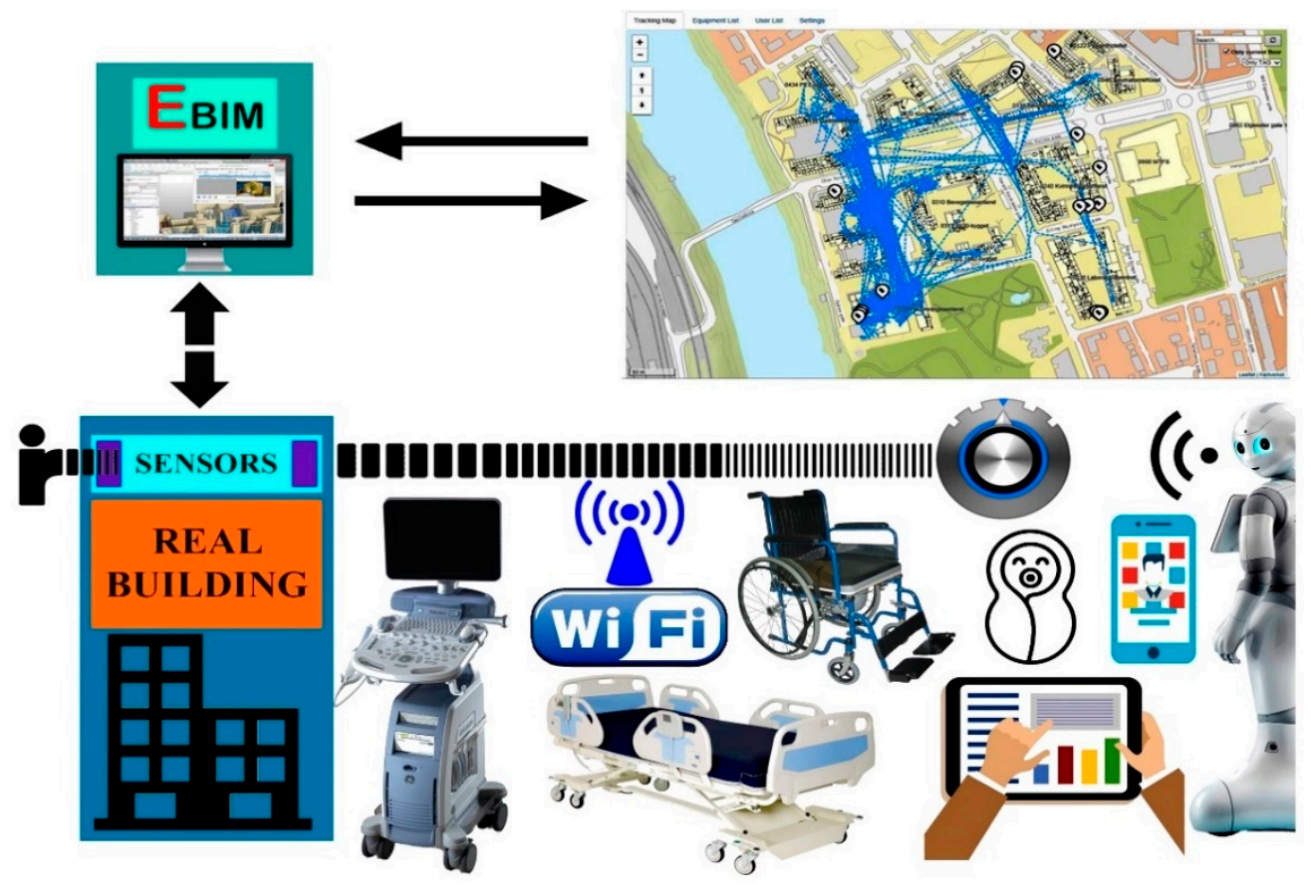

Figure 1. Schematic view of an indoor positioning system (IPS) system and the role of enterprise building information modeling (EBIM) in St. Olavs Hospital. The Internet of Things (IoT) can be used to streamline the hospital performance. Using location systems makes it easier to keep track of where different types of equipment are located. In this regard, EBIM is a virtual representation of the building stock and is a process-driven approach with a holistic business perspective. 
Healthcare managers are continuously dealing with subjects that are related to the safety of their amenities, the contentedness of their employees, the quality enhancement and improvement of the standard grade of care provided to their patients, the pricey workflow and the inefficiencies of costly processes that affect their bottom line. Many a time, information technology (IT) innovations for the healthcare system are listed as potential tools for improvement. Pioneers and researchers are constantly working to make new technologies that could support business operations and enhance the quality of activities. Today's healthcare facilities are faced with the augmentation of patient numbers as well as higher expectations for patient experiences and the level of satisfaction as an important outcome of healthcare services. To meet these rising requirements, eliminating the wasted steps and making a simpler workflow is a necessity. One of the main components to achieve an efficient workflow is asset tracking and management. When employees are under duress, they do not have enough time to find medical equipment such as IV pumps and patient-monitoring devices. Hence, IPS is one of the more recent and effective ways of addressing these challenges, such as integrating real-time location systems (RTLS) into hospital processes [6]. Accordingly, to pinpoint the device's location and users inside the building, small devices, such as beacons, act as sensors or hot spots supported by Bluetooth low-energy (BLE) wireless technology. Depending on the system in which they are applied, beacons are active or passive devices which send out a single signal that is interpreted by other devices to facilitate distance identification. The sensors provide extremely accurate locational tracking [5].

This paper presents a study related to indoor positioning systems (IPS), which is a development in the field of smart facility management based on enterprise BIM (EBIM). By considering BIM as a model of digital interaction for different types of properties through all stages, where everyone can initially share and visualize through different digital interfaces, the focus is changed greatly from project-centric to see BIM in a business perspective. In this regard, St. Olavs Hospital, together with the Central Norway Regional Health Authority (HMN) initiated a project entitled Life-Cycle BIM based on facility management. The concept of this is called enterprise BIM (EBIM or business BIM), and its main emphasis is on integration, information sharing and openness across business structures. In fact, this is the most important originality and innovative aspect of this study. EBIM is a concept that obeys and follows the strategy of the OpenBIM [7] standard during a building's life cycle, and it aims to optimize and improve business management, knowledge sharing, digital interaction and connection in the different phases of the projects. For this purpose, this study is focused on a tracking system at St. Olavs Hospital as a case study and reviews the necessity of a survey system based on the wireless field that is recognized in the course of a real process of establishing a spatial management system for large facilities. Accordingly, the ultimate goal is to develop the management system based on devices that can collect up-to-date data in large building complexes for facility management purposes.

\section{Literature Review}

The sudden population growth has created many challenges in the healthcare system. Resolving these challenges and providing a quick solution based on restricted resources is a serious need [8]. The Internet of Things (IoT) predicts a future that anything/anyone/any service can be connected by means of relevant and suitable information and communication technologies, which will lead to a technological revolution in the areas of domestics, smart homes, healthcare systems and goods monitoring. The IoT embodies the concepts of inclusive, all-encompassing and ambient computing that have evolved over the past two decades and have now reached some extent of maturity. The IoT is considered as a network of billions of people, objects, and machines interacting with each other, invisibly communicating with sensors, and playing a functional and an effective role in day-to-day life [9]. The IoT elevates a strong domain as one where embedded devices and sensors can link and exchange information over the Internet [10]. The future will be mastered by the IoT, which will serve as a worldwide platform for linking physical objects, things and people. Therefore, it has the ability of enabling new ways of functioning, operating, communicating, interacting, entertaining and living [9]. Hence, connecting the IoT with mobile technology and networks offers acceptable results on account of 
their cost-effective and user-friendliness [8]. Today, we live in the age of smart technologies that show a pervasive level of computing everywhere. The IoT has appeared as a flourishing field for revealing this new type of technology [11]. Nowadays, Internet technology is pervasive in our society and permeates in all aspects and areas of our lives, and it is better to consider it as an essential requirement and not as a convenience [9]. In 1991, Mark Weiser described the future prospects of the Internet functioning as "ubiquitous computing" [11]. In this regard, he in "the computer for the 21st century" points out that "ubiquitous computing" does not just mean computers that can be moved to the beach, forest or airport. It means that these devices and others are connected to each other in a network and help to better understand the final form of comprehensive computing everywhere [12]. From this perspective, he focused on how a smart livable environment can be activated by integrating mobile technology that supplies an effective and strong instrument in multimedia systems. Kevin Ashton is one of the forerunners of the IoT. He categorized the IoT into three paradigms: 1) Internet-oriented, 2) things-oriented, and 3) semantic-oriented. In 1999, Neil Gershnefeld, in his book "When Things Start to think", talked about similar things at the Massachusetts Institute of Technology, MIT Media Lab [11]. Kevin Ashton introduces the IoT as an evolving architecture of the Internet and world-wide information services [9]. In fact, the definition of IoT depends on whom you are talking to, but it can be officially defined as a dynamic global network infrastructure with its own structure and interactions. In simple terms, IoT means the capability to create everything anywhere near us and it is expected to link to the Internet with a smart behavior by considering the type of independence and privacy. In general, the IoT incorporates three main requirements: first, a common comprehension and awareness of the status of end-users and their applications. Second, software architecture and comprehensive communication networks to cover and process a variety of data and, finally, analytical instruments in the IoT that target to self-governing and smart behaviors [11]. Everyday changes and development in healthcare activities and the intricacy of medical centers, beside the creation of new technologies, make changes and evolutions in the requirements and performance of buildings [13]. In this regard, the influence of the IoT has changed in all aspects of life, but its effect on the healthcare system is significant due to the transition from its margins. The primary purpose of the IoT-based healthcare services is to achieve a cost-effective experience in all aspects and living standard improvements [8]. The Internet revolution has been led to the interlinking and interaction between humans on a remarkable extent. The future of the IoT revolution is the cross-connection between things with purpose to make a smart revolutionary environment. Leading investigators in the late 1980s set out to create a human-to-human connection through the computational technology of common calculations, which aims to facilitate day-to-day life through this technology. In fact, the smart environment defined by Mark Weiser is a rich and invisible physical world intertwined with sensors, stimuli, displays, and computational elements, and it is embedded as an integrated system through the linkage of a continuous network to the day-to-day stuff and objects of our lives [14].

\section{Research Methodology}

The research method chosen for this study is a case study [15] focused on IPS implementation in a holistic organizational aspect structure during the entire life cycle in the healthcare industry at St. Olavs Hospital. Through this method, we try to survey the mechanism of using of IPS and BIM in FM based on the concept of EBIM. Accordingly, EBIM is presented, which is adapted where all buildings are an integral part in the entire portfolio of buildings, as well as the aspect structure defined in the hospital business structure. In the following, the paper considers the relevant literature review and introduces the technologies that lead to the performance of EBIM IPS in the case study. A primary source of information of the present study is the academic master theses at the Norwegian University of Science and Technology (NTNU), department of computer science and scientific reports at St. Olavs Hospital. During the study, the authors conducted several meetings at the real-estate department at St. Olavs Hospital with technicians and substantive staff who helped to understand of the context of this case. According to the objectives of this study, the methodology of this study could be defined in order 
to develop and improve a practical approach which provides operational knowledge that could be integrated in the smart facility management in the context of the healthcare industry.

\section{What is Enterprise BIM (EBIM)?}

Healthcare is regarded as the fastest developing trade and a major service industry in the world. Therefore, to keep up with this expansion, the healthcare industry should modify and shift its traditional operations and utilize a new information system to handle unpredictable processes and deploy detailed answers in a timely manner [16]. Recent advancements in technology and communications have had a direct impact on the facility management field, which has disrupted traditional practices and created a range of alternatives and selections for facility managers [17]. St. Olavs University Hospital is made up of many buildings and both old and new buildings have been incorporated in this complex, which has to be kept in proper or good condition in the course of the decades of its lifetime. With this matter at hand, the hospital needs to identify a homogenized and standardized open platform with a view to develop and maintain its amenities. Simultaneously, with St. Olavs University Hospital, Central Norway's Health Authority set up a project called Life cycle BIM in 2012, with the aim of creating a life cycle BIM based on a facility management platform [18]. In fact, BIM implementation in the life cycle of a project incorporates and merges precise and reliable data for building management and offers outstanding business value in the operating period. By using BIM, it is possible to document and manage all building details and use model data to govern the systems performance [19]. Hence, the result was to carry out an EBIM philosophy, where all buildings are an integral part in the entire portfolio of buildings. Using such a solution enables the integration of core business and the various processes of the hospital [18]. EBIM is a discrete information database at St. Olavs Hospital, which is aimed to support significant aspect structures of the user, such as property management, FM and virtual design construction (VDC). As illustrated in Figure 2, EBIM will support important functions in the core business and it will be an important source for strategic management analysis in the near future [20]. Hence, IPS as an auxiliary arm in FM along with other features will assist in achieving and realizing the goals of EBIM (Figure 1) [18]. One of the advantages of using BIM is the possibility to sort out the required data and present them for the user in different settings. With the help of positioning data and saving them in a BIM database, it can be possible to present the data on 2D or three-dimensional (3D) maps, which will assist in realizing the goals of EBIM. St. Olavs University Hospital is internationally recognized in using database technology to describe virtual building models. All buildings of St. Olavs Hospital (which is approximately 350,000m2) have been modeled according to the openBIM standards. St. Olavs Hospital has an enormous capacity and potential to observe the resource management, organizational management and the development of the concept of workflow. A particular and major focus will be on how the use of BIM models and position technologies can enhance the quality of FM, including how rooms and resources are utilized and what quality is achieved as an outcome [18].

Three-dimensional models and BIM are already in widespread use in construction projects. Enterprise BIM or EBIM is a continued solution with an emphasis on digital collaboration and sharing of all building-related information where core businesses and building owners can use the potential of ownership of information throughout the lifetime of the building. Enterprise BIM is the concept where the virtual building and building processes are used throughout the lifetime of the building, and the outdoor environment is combined with sensors and the companies' own work processes. Consequently, building owners will have a unique decision basis for optimizing the use and operation of the building stock (Figure 2).

Nowadays, large building complexes and campuses, such as hospitals and universities, often need detailed and exhaustive BIM-skilled workers in order to build, as well as for management. BIM could also be used to maintain and support the core business processes of an organization or company. BIM is frequently employed in cases involving construction, but it is barely utilized after the construction phase is accomplished. By using BIM in combination with IPS, the maintenance of 
equipment could be conducted on a regular basis. Hence, for example, robots could know where and when it is necessary to clean floors in a building, and (re)construction or renovation could be based on flow data in different phases of a building. The following sections discuss the combination of BIM with IPS and the advantages of and thoughts regarding future areas of the use of BIM [18].
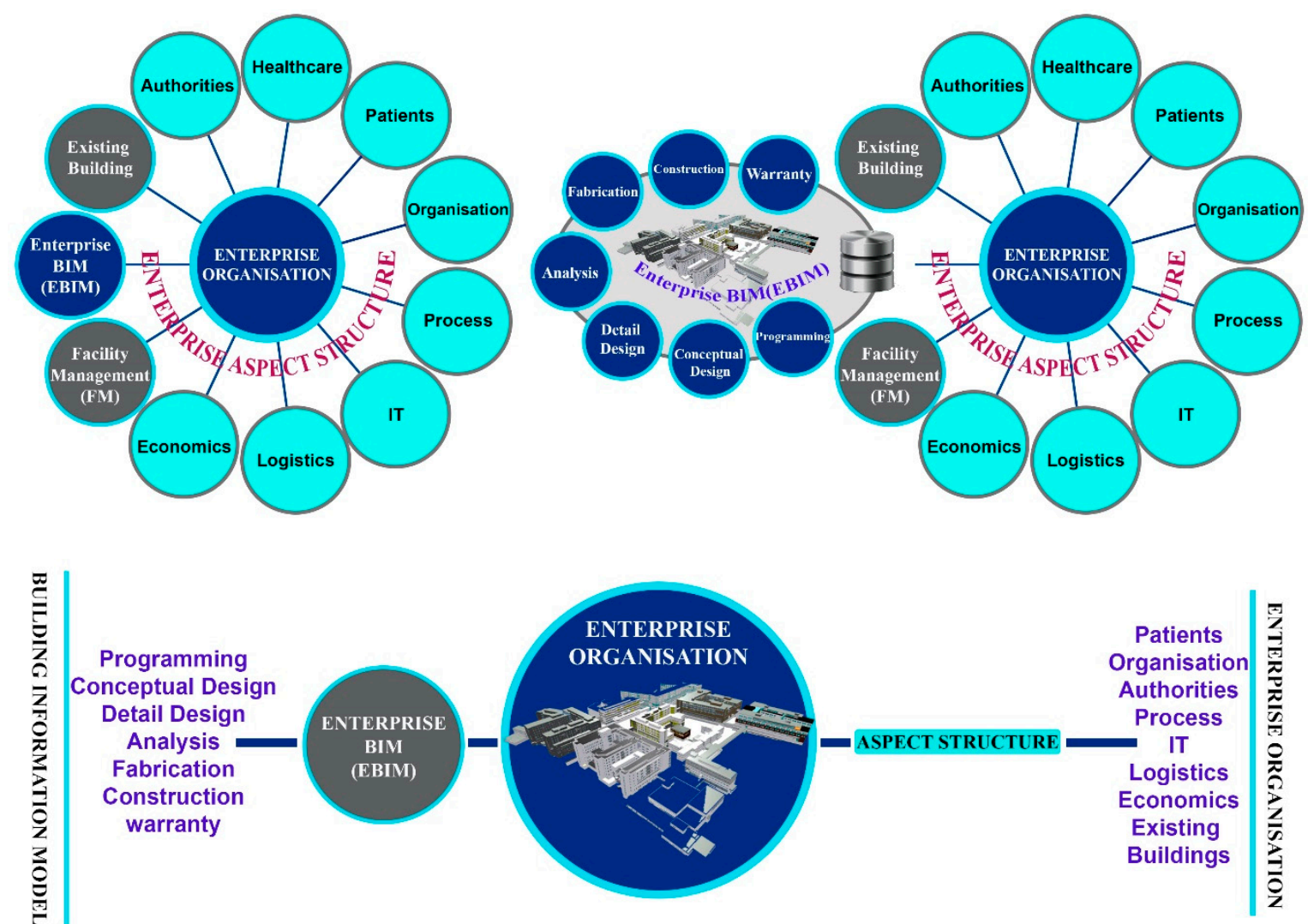

Figure 2. Enterprise BIM as an aspect structure. Creating EBIM as an independent structure instead of a part of the FM system gives BIM a more prominent position in the enterprise. Hence, EBIM is submitted as a distinctive and unique aspect structure in the system. The images demonstrate how a building project employs the same data infrastructure and framework as the enterprise itself.

\section{IoT Devices and IPS}

The IoT is an interlinked system of devices that interact and co-operate with humans or other physical objects and systems, where communications among machines can be carried out without human monitoring or interrelationship [21]. The latest advancements and development in technologies such as wireless sensors, BIM, IoT and data processing have provided the possibility to change the way of interacting with the built environment and to enhance the experience and expertise for the final users and service suppliers [22]. Integrating real-time data from IoT devices with BIM provides a strong and forceful pattern for applications to develop and enhance construction and operational productivity [23]. The IoT focuses on enabling connections across all devices, things that are virtual or exist in real life. An IoT ambience is similar to the nervous system in terms of information communication. In each mode change, the "thing" generates information about its new position [24]. IoT devices and sensors are progressively and ever more being allocated in the built environment and industrial applications. The built environments reflect approximately all perspectives and aspects of human life, from healthcare to industry and education, where BIM is developing quickly and increasingly as a platform for information transformation and management. BIM models are employed throughout the project life cycle, and they provide an opportunity to create open platforms that harmonize and synchronize with 
various information sources, such as building automation systems and wireless sensors. In fact, as a core platform, BIM is an important technology when considered from the perspective of IoT integration [22].

IPS is about the location in the context. Comprehension that the location has a connection to other things provides the possibility to give meaning and sense to that location. Those "other things" are exactly what is employed to characterize and show the form or outline of the location both in space and in time. They can be coordinator in a measurable system and play a role as a focal point, such as Earth geographical positioning or positions connected to visible things, such as landmarks, people or objects. Positioning data are information regarding the location at a specific place and time, and in a particular context [25]. In fact, IPS is a system for finding objects or persons in indoor spaces by using various technologies, methods and information, such as radio waves or sensor information from mobile devices. IPS can use a wide variety of technologies that are different and applicable to different scenarios. A term related to IPS is called real-time locating systems (RTLS) [26]. RTLS can be considered as a computing-based application. It is recognized as a new application that enhances the operational productivity of administrative and managerial processes [16]. In fact, RTLS could be defined as any solution that is employed to automatically identify and track the location of an asset and create alerts through every stage of the process. RTLS solutions consist of various labels, badges, operating systems (Wi-Fi, infrared, Bluetooth low energy, low frequency, ultrasound and others), network devices as well as other components such as servers, intermediaries and end-user software [26].

RTLS in the healthcare industry is a system utilized to put out immediate tracking or real-time management of medical devices or equipment, staff and patients in all types of patient care environments. In addition to determining the position of the assets, the system uses locating technology that integrates readily with other healthcare IT solutions and it empowers facilities to improve workflow, while help in in regard to cost reduction and improvement in clinical quality. RTLS systems typically consist of location sensors that are linked to several assets, whether patients, staff, or a piece of equipment. Using a singular identifier, the system can find the labels and provide real-time information about its location in the center. RTLS solutions based on estimation can empower tracking in a hospital's unit or floor, while clinical systems are able to attain rooms, beds and even shelf-level tracking for true workflow automation [6]. In RTLS, the positioning engine software communicates with location sensors and labels to specify the position of tagged assets and persons. The engine transmits this information to specialized intermediary applications [27]. On the other hand, RTLS is any solution that is utilized to automatically detect and track the position of an asset, person, or other object in real time [6].

\section{Case of Study: IPS at St. Olavs Hospital}

As previously mentioned, Central Norway Regional Health Authority has an overall EBIM (enterprise BIM) strategy in which all buildings in the health enterprises are described and communicated virtually on a uniform openBIM standard throughout the entire life cycle of the building. The purpose is to strive for a comprehensive and rational digital management of the building stock that reflects to the best possible level the real building structures and functions. The main difference between BIM (which is mainly project- and FM-oriented) and EBIM is that EBIM is a building aspect structure that puts the core business into focus (owner, director, personnel, patient, authorities, manager and builder). In order to meet this objective, a BIM server has been acquired for St. Olavs Hospital, and is used as the main tool for validating, storing and retrieving all building technical information. The system has features that support operation and maintenance, rental agreements, retrieval and tracking of mobile equipment and people, as well as an in-house web-based real-estate portal and wireless communications in the field. St. Olav's Hospital has a strong focus on how EBIM can support its core business operationally and strategically [28]. To make EBIM more knowledge-based, central operation monitoring with the help of sensor technology, such as the IoT, will have a fundamental role on decision-making, object tracking, optimizing inventory space and labor and operational costs [20].

In order to develop and enhance the quality of the FM, St. Olavs Hospital has a need to locate medical equipment. Big and massive equipment like AGV (automated guided vehicle) robots, hospital beds and 
wheelchairs tend to move relatively frequently (Figure 3). Although these are easy to spot, it still takes time to locate and position them across a building. Smaller medical apparatus and equipment are often borrowed from one section within the hospital to another and, in some cases, they are never returned. This causes the facility managers to seek them, wasting valuable time. Hence, a system for locating and positioning the apparatus and equipment faster is very welcome from all the sections of the hospital. Accordingly, facility managers and hospital architects are also interested and concerned in the historical data related to the locating system, because they can employ it to evaluate the requirements for equipment maintenance or building upgrades. In the next steps, it is possible to track the doctors and the patients, (there are obvious security issues related to this that one must be aware of) for example, to check in which room they were or moved to and from. This would require a more precise triangulation in the system, unlike positioning medical apparatus and equipment, notably in emergency cases. Positioning systems are costly and should cover a large indoor space. Wi-Fi is usually installed in large building complexes before developing IPS. This is also the case at the hospital, where the managers show enthusiasm in regard to utilizing the technology as closely as possible [26].

St. Olavs Hospital employs useful techniques and technologies in the field of IPS and most of them rely on the utilization of 2D floor plans, projected from 3D IFC (industry foundation classes) $[29,30]$ models. In this case, St. Olavs Hospital uses a database system to manage life cycle information from planning to FM that is built to handle complex openBIM models (Figure 3).

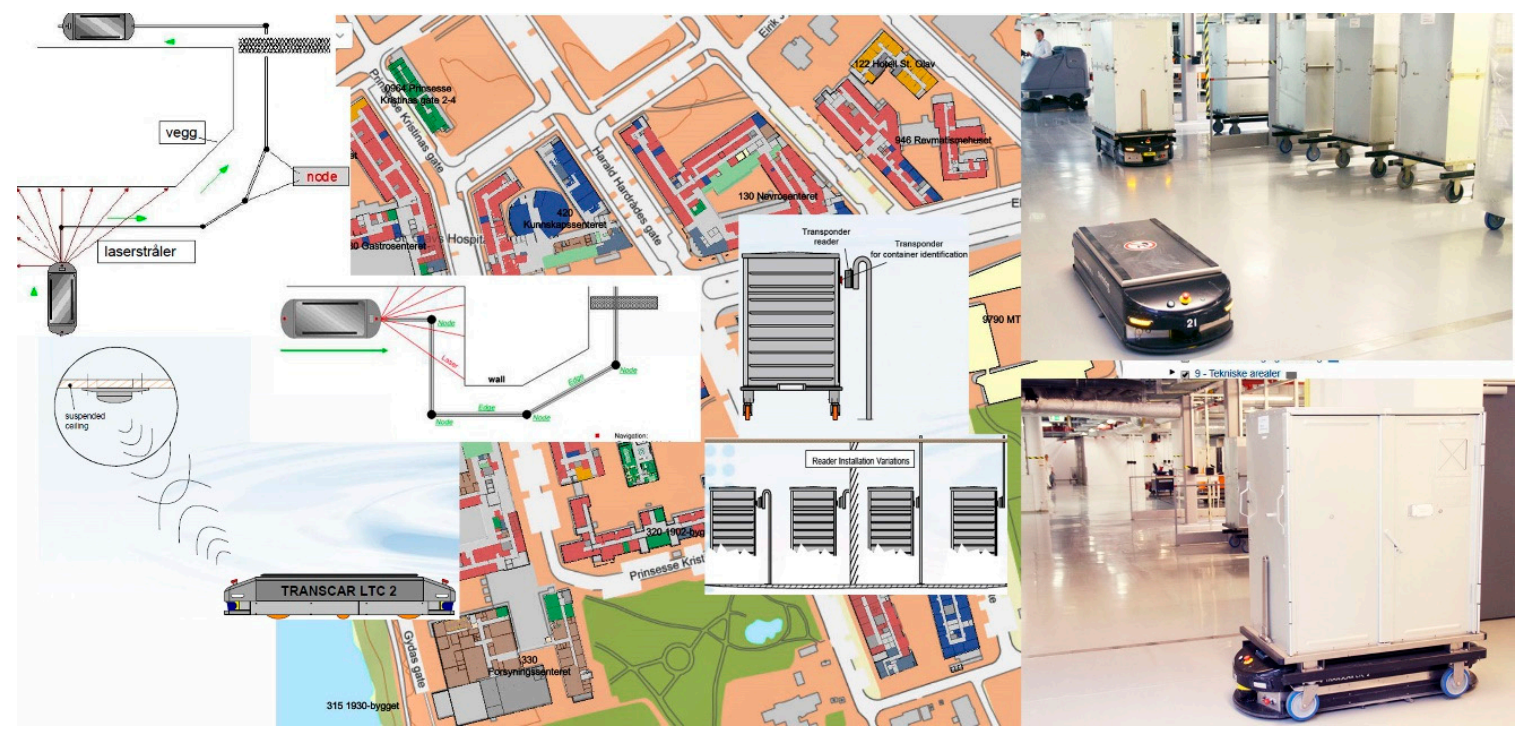

Figure 3. Automated guided vehicle (AGV) layout and robots. AGVs have been used at St. Olavs Hospital for several years. For example, in the cleaning section, a self-cleaning robot has been tested for floor washing, which ensures good quality and proper washing at appropriate levels.

\subsection{Model Server Manger (MSM)}

In order to visualize and manage of St. Olavs University Hospitals EBIM, an application called MSM (Model Server Manager) is used [18]. In this application, every old, new and future building is an integral unit in all building portfolios [20]. Hence, as part of their IT-related activity, a suite of model-driven database systems called EXPRESS Data Manager (EDM) [31] has been developed. EDM is a database server based on the EXPRESS data modeling language. It uses industry foundation class (IFC) models that are mainly employed with the purpose of sharing all data [32]. Since all models of St. Olavs Hospitals Buildings are stored in the database, MSM finds and recovers building models and all associated data from the database installed on the model server, and it enables for end users to see numerous buildings simultaneously [18]. 


\subsection{Mechanism of Performing of EBIM IPS in St. Olavs Hospital}

In general, IPS is related to technologies that facilitate the network of devices to locate objects and people. In this regard, location engines have a key role in estimating and calculating the position of an object being tracked [26]. The location can be computed by using a combination of geometry, topography, and algorithms filters. Cisco Mobility Services Engine (MSE) [33] is a location engine that is used to gather tracking data from different environments and employs them in other applications. It can be run as a physical or virtual device and obtain data from RTLS tags which are linked to the Wi-Fi network. RTLS tag beacons are collected by one or more Wi-Fi access points (Wi-Fi AP) and the picked-up information is used to compute and estimate the position of the tags. By using Wi-Fi hotspots in a building for interior spaces, multipurpose use is possible. It is important to position Wi-Fi $\mathrm{AP}$ in a way that enhances the accuracy of the measurement. This means that Wi-Fi AP should be located near walls and, in the case of large spaces, they should be placed in the center of the room (Figure 4) [18].
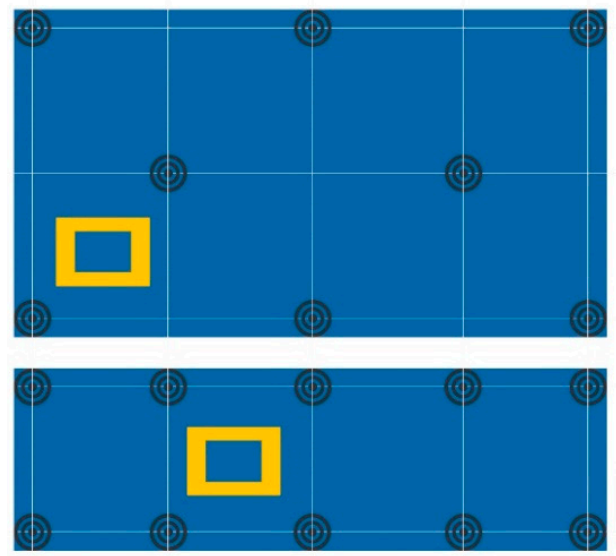

Recommended arrangement
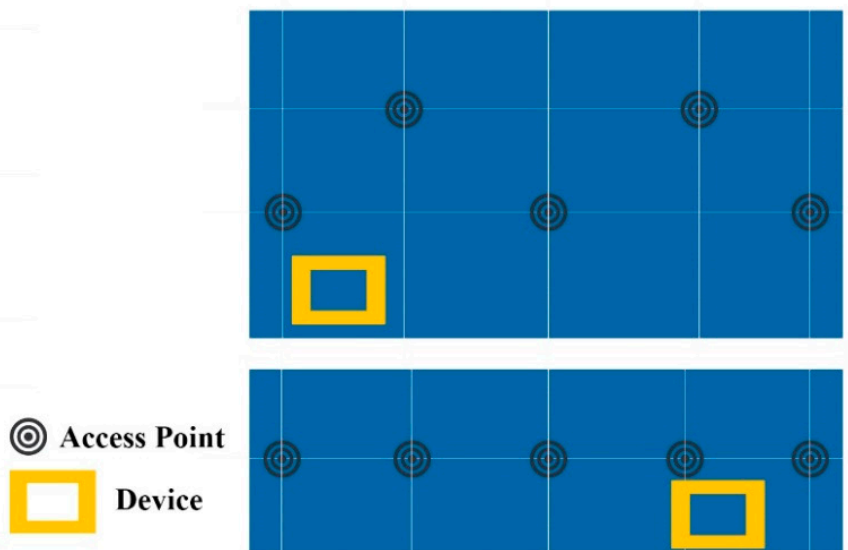

Not recommended arrangement

Figure 4. Simple illustrations summarizing the access point placement concepts. Adapted from [18].

In St. Olavs Hospital, Cisco MSE obtains the relevant data from AP on the Wi-Fi network and uses the time difference of arrival (TDOA) and received signal strength indication (RSSI) to compute tag locations. Accordingly, Cisco MSE computes positional floor plan coordinates for the tag based on TDOA and RSSI. The precise positioning data for the tags are sent by using a TCP (transmission control protocol) stream from the Cisco MSE server to the model server, where the Windows service is running. The Windows service is installed on the model server with the aim of obtaining the location of data as a TCP stream from the Cisco MSE server. The service loops constantly and it waits for new information to arrive. When data are imported, it strives to process them and save any XML (extensible markup language) files, before waiting for more information. Indeed, the files received by the Windows service from Cisco MSE must be analyzed and imported to the EBIM system. Therefore, it is necessary that all received XML files have all the attributes and values in each of them. Positioning data are ultimately visualized for the end user through a web application known as the St. Olavs Eiendoms portal. It allows users to search for and find their equipment with a mounted tag at the hospital [18].

In other words, the TCP stream service creates a communication with Cisco MSE and collects the data stream collected from the asset tags (Figure 5). Subsequently, the required data will be written by the service to an XML file that contains features such as the current location and time, and stores it in a defined folder [26]. When data are saved as objects in the database, the objects must be linked to the structural model in which they are located. In this instance, tags as an object have potential to move among different buildings of the hospital, and they present the possibility to switch between the building models that they belong to. When a tag is inserted into the database as an object, it is presented with numerous attributes. Then, more features can be assigned to the tags, such as IDs for 
equipment mounted on them. The tags are saved as devices with all tracking records which are linked to each tag. Each time a tag sends a beacon, it indicates its location and the tracking data are saved as a track record for each tag. The track records are added to a list for the appropriate tag, and they provide the possibility to see the tag's position. The main features in these track records are time, floor, longitude and latitude. The time stamp creates information about the time that the tag sent its location. The floor feature is connected to a unit called "Floor", which connects the values of "floor Ref-ID" from the XML files to the actual floors in the building models, and at the end the latitude and longitude create $x$ and $y$ coordinates for the tag (Figure 5) [18].

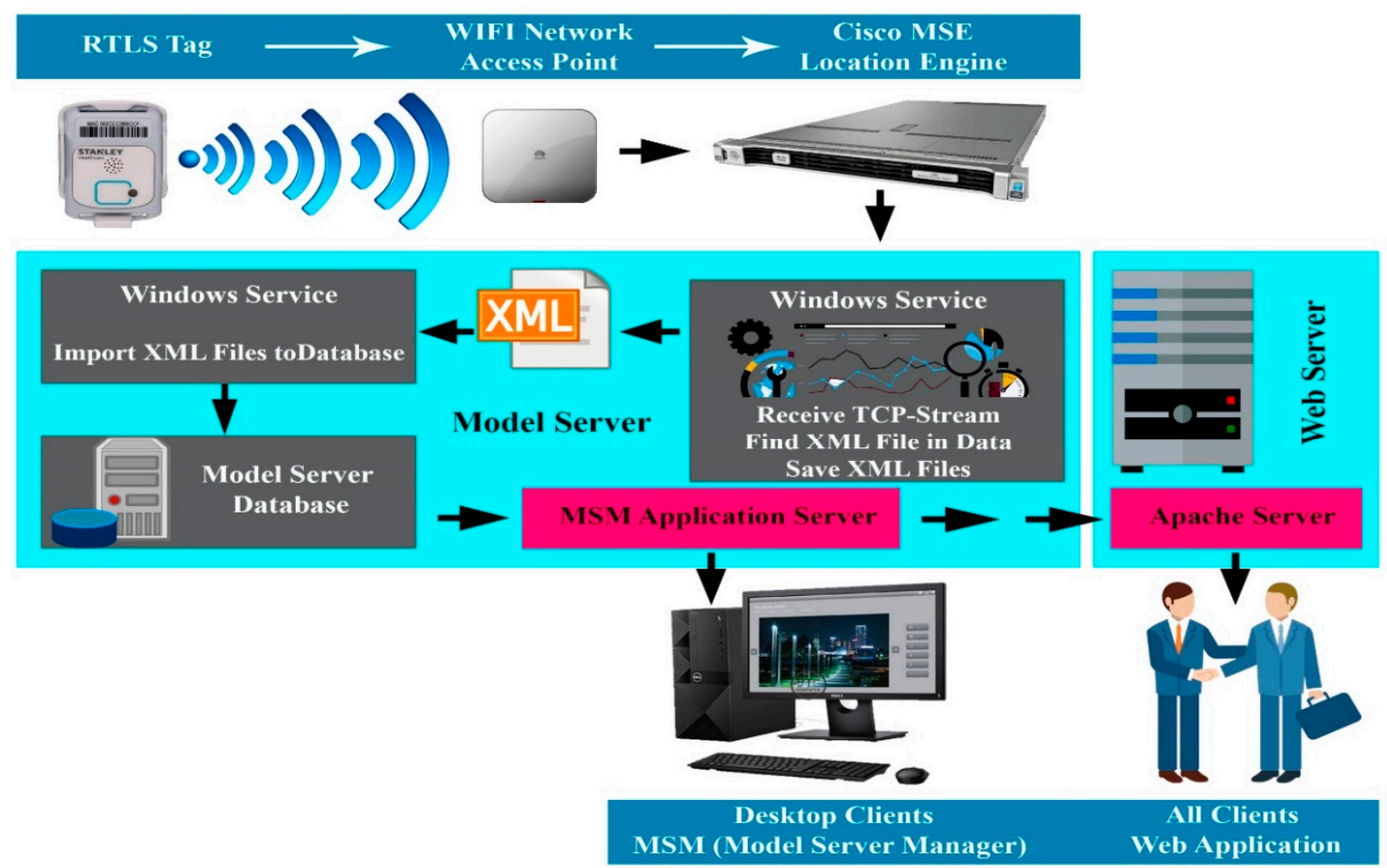

Figure 5. Data sharing in IPS. Adapted from [18]. The image shows the set of components of the system and the information flow mechanism in the developed IPS from the first points to the visualization of data for end users.

In following, the BIM tracker has the responsibility to read, rewrite and store the Cisco MSE data in BIM models and it leads to the creation of an IFC object from the tracker and puts it in the correct IFC model. The tracker is a service to update constantly found geo-references, the current floor and the time in the BIM models. This service also logs all positioning data in a history folder and tracks all available readable data. The tracker put its data from Cisco MSE in the BIM server, where there is a repository for all models. Based on the authorizations, the user can also make modifications and alteration to the model values. Therefore, MSM is mostly used by architects, developers, and other key stakeholders. Finally, a web browser application (St. Olavs Eiendoms portal) has been developed to present the models with tracking data in a more user-friendly ambience. The BIM server is accessible to all users, and they can view all tracking devices stored in a 2D map [26]. The accuracy created by IPS, irrespective of the technology at hand, may differ depending on the method used to estimate the positions [5]. In any IPS, precision is a key and crucial factor in determining the functional efficiency of the system [18]. Choosing an estimation method commensurate with the selected IPS enables resource optimization, since the number of readings depends on the number of integrated beacons in the network [5]. IPS abilities are made possible by various technologies, and most IPS models use a combination of technologies to perform their function [25]. The variety of different technology solutions for IPS indicates how the field of communication is deeply interdisciplinary and demonstrates that nearly any signal, technique or sensor can be used to achieve this goal [5]. 


\section{Conclusions}

The commercial advantage of IPS is significant due to the increase in the asset value, it clearly helps users to find and use the equipment and facilities easily and, finally, it enhances functional efficiency. Especially, in hospitals, finding emergency facilities in seconds rather than minutes can be a matter of life and death. At St. Olavs Hospital, everything is centered around patients, and tracking equipment such as wheelchairs and beds is in line with this. From this standpoint, all facilities are equipped with IoT devices, and they can communicate directly over the Internet and all components can report their condition and contribute to better utilization of resources. With proper use, this leads to obvious opportunities for a better and efficient performance. St. Olavs Hospital, as a health enterprise, has an operational web-based real-estate portal as an interface to the organization and model server. The real-estate portal has features such as deviation notification, property overview, maps, mobile equipment tracking, room classification and rental information, all based on model server data. These findings indicate that the implementation of IPS integrated into EBIM creates efficient use of the available facilities and benefits and makes opportunities for hospitals and other large buildings. In healthcare management, issues related to the safety of the facilities, the quality of care provided to patients, the staff satisfaction and the costly ineffectiveness of workflows are of the most importance. Therefore, IT-based innovation for healthcare is recognized as a potential tool for improvement. Hence, St. Olavs Hospital is constantly striving to develop technologies and systems to support easier business activities that ultimately lead to improved service delivery. This approach has a direct impact on FM and provides a wide range of options and better communication for facility managers.

This study is based on a prototype implementation and, thus, the results are limited to exploratory studies using a limited amount of equipment and time. In the future, St. Olavs Hospital will enhance the use of BIM data with IPS and other technologies to achieve better facility management, such as tracking the movement of medical equipment, optimized fleet management and logistics. Furthermore, the data from the indoor positioning system will be used in EBIM to provide better services for the healthcare personnel and patients and for better decision-making at the strategic and operational levels of the hospital. The main goal is a comprehensive achievement towards rational and logical digital management of buildings that can reflect the engineering structures and performance of buildings and infrastructure in the best way possible while providing a wide range of benefits and services within a good working environment to owners, facility managers, and inhabitants. In this regard, the mechanism of performing of EBIM IPS leads to a systematic review of results and regular evaluation that helps the healthcare industry to create and plan hospitals based on a conscious attitude, which results in the support of good services and functional efficiency enhancement.

Author Contributions: Conceptualization, T.Å.E.; methodology, T.Å.E., S.A.P. and S.R.H.R.; formal analysis, T.Å.E., S.A.P. and S.R.H.R.; investigation, T.Å.E., S.A.P. and S.R.H.R.; writing-original draft preparation, S.R.H.R.; writing-review and editing T.Å.E., S.A.P. and J.K.; visualization, T.Å.E. and S.R.H.R.; supervision, T.Å.E. and J.K. All authors have read and agreed to the published version of the manuscript.

Funding: This research was funded by ERCIM "ALAIN BENSOUSSAN" FELLOWSHIP PROGRAMME and in collaboration with NTNU-Norwegian University of Science and Technology as the host organization.

Acknowledgments: S.R.H.R. acknowledges the financial support from the ERCIM “Alain Bensoussan” Fellowship Program. The authors would like to thank the St. Olavs Property Department for their support.

Conflicts of Interest: The authors declare no conflict of interest.

\section{References}

1. Pasek, J.; Sojkova, V. Facility Management of Smart Buildings. Int. Rev. Appl. Sci. Eng. 2018, 9, 181-187. [CrossRef]

2. Service Futures. How IoT and Smart Cities are Game Changing Facilities Management. Available online: https://www.servicefutures.com/iot-smart-cities-game-changing-facilities-management (accessed on 11 June 2020). 
3. See, J. Smart Buildings: An Integrated Future for Facilities Management; Whatsnextcw, 2018. Available online: https://www.whatsnextcw.com/smart-buildings-an-integrated-future-for-facilities-management/ (accessed on 10 November 2019).

4. Fagerland, W.T. Assessment of Indoor Positioning System (IPS) technology. Master's Thesis, University of Oslo, Oslo, Norway, 2010.

5. Mier, J.; Jaramillo, A.; Freire, J. At a glance: Indoor Positioning Systems technologies and their applications areas. In Proceedings of the International Conference on Information Technology \& Systems, Quito, Ecuador, 6-8 February 2019; pp. 483-493. [CrossRef]

6. Centrak. RTLS vs. RFID—The Common Misperception. 2019. Available online: Centrak.com.https://www.cent rak.com/rtls-vs-rfid/ (accessed on 20 October 2019).

7. Building SMART International. Open BIM. Available online: https://www.buildingsmart.org/about/openbim/ (accessed on 18 July 2020).

8. Nazir, S.; Ali, Y.; Ullah, N.; Magariño, I.G. Internet of Things for Healthcare Using Effects of Mobile Computing: A Systematic Literature Review. Wirel. Commun. Mob. Comput. 2019, 2019, 1-20. [CrossRef]

9. Tyagi, S.; Agarwal, A.; Maheshwari, P. A conceptual framework for IoT-Based healthcare system using cloud computing. In Proceedings of the 2016 6th International Conference-Cloud System and Big Data Engineering, Noida, India, 14-15 July 2016; pp. 503-507. [CrossRef]

10. Azzawi, M.A.; Hassan, R.; Azmi, A.; Bakar, K. A Review on Internet of Things (IoT) in Healthcare. Int. J. Appl. Eng. Res. 2016, 11, 10216-10221.

11. Hassan, Z.; Arafat, A.H.; Badawy, M.; Ali, Z. Internet of Things (IoT): Definitions, Challenges, and Recent Research Directions. Int. J. Comput. Appl. 2015, 128, 37-47. [CrossRef]

12. Weiser, M. The computer for the 21st Century. Sci. Am. 1991, 265, 94-104. [CrossRef]

13. Soliman Junior, J.; Baldauf, J.; Formoso, C.; Tzortzopoulos, P. Using BIM and Lean for Modelling Requirements in the Design of Healthcare Projects. In Proceedings of the 26th Annual Conference of the International Group for Lean Construction (IGLC), Chennai, India, 18-20 July 2018; pp. 571-581. [CrossRef]

14. Rahman, M. Smart Hospital System Depending on IoT. 2016; 7. Available online: https://www.academia.edu /25158626/Smart_Hospital_System_depending_on_IoT (accessed on 4 May 2020).

15. Yin, R. Case Study Research Design and Methods, 5th ed.; SAGE: Thousand Oaks, CA, USA; Los Angeles, CA, USA, 2014; p. 282.

16. Ma, X.; Yang, K.; Brayley, K. RTLS-Based Ubiquitous Healthcare Management System Design and Implementation. FRID J. 2011, 24. Available online: http://hse.eng.wayne.edu/Research/UbiquitousH ealthcareManagementSystemDesignImplementation.pdf (accessed on 2 February 2020).

17. ABIResearch. Role of Facilities Management in Smart Buildings. 2016; ABIresearch for Visionaries. Available online: www.abiresearch.com (accessed on 10 March 2020).

18. Øgård, A.E. Indoor Positioning Integrated in EBIM. Master's Thesis, Norwegian University of Science and Technology (NTNU), Trondheim, Norway, 2016.

19. Panagiotidou, N. Lifecycle BIM and FM. breakwithanarchitect. 2018. Available online: https://www.breakw ithanarchitect.com/post/lifecycle-bim-and-fm (accessed on 3 June 2020).

20. Van der zwart, J.; Evjen, T.Å. Data Driven Simulation Model for Hospital Architecture Modelling and simulating clinical process, architectural layout and patient logistics in a hospital's Building Information Model. Chapter fourteen. In Formal Methods in Architecture and Urban; Leite, V.D., Morais, F., Vieira, V.J., Eds.; Cambridge Scholars Publishing: Cambridge, UK, 2018; Part III; pp. 223-236.

21. Ahmadi, S. Chapter 6-Internet of Things (NB-IoT and Massive MTC). In 5G NR Architecture, Technology, Implementation, and Operation of 3GPP New Radio Standards; Elsevier, Academic Press: Cambridge, MA, USA, 2019; pp. 747-787. [CrossRef]

22. Dave, B.; Buda, A.; Nurminen, A.; Främling, K. A framework for integrating BIM and IoT through open standards. Autom. Constr. 2018, 95, 35-45. [CrossRef]

23. Tang, S.; Shelden, D.; Eastman, C.; Pishdad, B.P.; Gao, X. A review of building information modeling (BIM) and the internet of things (IoT) devices integration: Present status and future trends. Autom. Constr. 2019, 101, 127-139. [CrossRef]

24. Isikdag, U. BIM and IoT: A Synopsis from GIS Perspective. ISPRS Int. Arch. Photogramm. Remote Sens. Spat. Inf. Sci. 2015, 40, 33. [CrossRef] 
25. Bernard, R. Indoor Positioning Systems. Secur. Ind. Assoc. 2017, 35. Available online: https: //www.google.com/url?sa=t\&rct=j\&q=\&esrc=s\&source=web\&cd=\&ved=2ahUKEwiK6sCix-vqAhUCwq YKHc69ChYQFjAAegQIBBAB\&url=https\%3A\%2F\%2Fwww.securityindustry.org\%2Fwp-content \%2Fu ploads\%2F2017\%2F11\%2FIndoor-Positioning-Systems.pdf\&usg=AOvVaw04nipReEgP8eNdzJTZZ3OG (accessed on 2 February 2020).

26. Kristian, J.F. Smart Hospital Combining BIM and Indoor Position System. Master's Thesis, Norwegian University of Science and Technology (NTNU), Trondheim, Norway, 2017.

27. Kamel Boulos, M.; Berry, G. Real-Time locating systems (RTLS) in healthcare: A condensed primer. Int. J. Health Geogr. 2012, 11, 25. [CrossRef] [PubMed]

28. Evjen, T.Å.; Hosseini Raviz, S.R.; Abbas Petersen, S. Enterprise BIM: A Holistic Approach to the Future of Smart Buildings. In Proceedings of the REAL CORP 2020: SHAPING URBAN CHANGE, Livable City Regions for the 21st Century, Aachen, Germany, 15-18 September 2020; pp. 251-260.

29. BuildingSMART International. Industry Foundation Classes (IFC)—An Introduction. Available online: https://technical.buildingsmart.org/standards/ifc/ (accessed on 5 July 2020).

30. ISO. ISO 16739-1:2018 Industry Foundation Classes (IFC) for Data Sharing in the Construction and Facility Management Industries_Part 1: Data Schema. Available online: https://www.iso.org/standard/70303.html (accessed on 6 July 2020).

31. Huse, P. FDVU/FM Med EDMmodelServer. Build. Smart Memb. Meet. 2015, 18. Available online: https://www.google.com/url?sa=t\&rct=j\&q=\&esrc=s\&source=web\&cd=\&ved=2ahUKEwir-uCG1OvqAh XMIIsKHR5FCTQQFjAAegQIBBAB\&url=https\%3A\%2F\%2Fbuildingsmart.no\%2Fsites\%2Fbuildingsm art.no\%2Ffiles\%2F04_jotne_bsnm-20150917.pdf\&usg=AOvVaw3Jr7qVKR6fY42_zU9E9Tsf (accessed on 25 June 2020).

32. Faizan, A. Evaluating Learnability and Accessibility of a Software for Engineers: Case of Model Server Manager (MSM) at Jotne. Master's Thesis, Universal Design of ICT, Oslo and Akershus University College of Applied Sciences, Oslo, Norway, 2018.

33. Cisco. Enterprise Mobility 7.3 Design Guide-Chapter: Cisco Mobility Services Engine. Available online: https: //www.cisco.com/c/en/us/td/docs/solutions/Enterprise/Mobility/emob73dg/emob73/ch13Loca.html (accessed on 18 July 2020).

(C) 2020 by the authors. Licensee MDPI, Basel, Switzerland. This article is an open access article distributed under the terms and conditions of the Creative Commons Attribution (CC BY) license (http://creativecommons.org/licenses/by/4.0/). 